Original Research

\title{
Quantitative Research on the Relationship between Salinity and Crack Length of Soda Saline-Alkali Soil
}

\author{
Jianhua Ren ${ }^{1 *}$, Xiaojie $\mathrm{Li}^{2}$, Kai, Zhao², Xingming Zheng', Tao Jiang² \\ ${ }^{1}$ Heilongjiang Key Laboratory of Remote Sensing Monitoring of Geographical Environment, \\ Harbin Normal University, Harbin, Chinaa \\ ${ }^{2}$ Northeast Institute of Geography and Agroecology, Chinese Academy of Sciences, Changchun, China
}

Received: 7 November 2017

Accepted: 12 February 2018

\begin{abstract}
The Songnen Plain in China has a typical type of soda saline-alkali soil that frequently shrinks and cracks under natural conditions, especially during water evaporation. This study aims to study the effects of salt contents on the cracking process of soda saline-alkali soils and to make a quantitative analysis between crack length and some primary salt parameters of soda saline-alkali soils. To achieve the objectives, 57 soil samples with different salinity levels were selected and a laboratory-controlled desiccation cracking test was then conducted. Next, correlation analysis was carried out between extracted crack lengths and salt parameters of all the specimens. The results showed that there are clear linear dependencies between crack length and salinity, $\mathrm{Na}^{+}, \mathrm{Cl}^{-}$, and electrical conductivity (EC), and that $\mathrm{CO}_{3}{ }^{2-}$ is also quite linear with crack length. The fitting results conducted from the verification experiment showed that $\mathrm{Na}^{+}$content, $\mathrm{Cl}^{-}$content, $\mathrm{EC}$, and total salinity showed high prediction performance $\left(\mathrm{R}^{2}>0.91\right.$ and $\mathrm{RPD}>2.5)$; that the $\mathrm{CO}_{3}{ }^{2-}$ content had quite reasonable accuracy $\left(\mathrm{R}^{2}=0.78\right.$ and $\left.\mathrm{RPD}=1.82\right)$ but with less stability and poor reliability; that the prediction accuracy for $\mathrm{pH}$, however, was very poor, with $\mathrm{R}^{2}$ and RPD only 0.42 and 1.06 , respectively.
\end{abstract}

Keywords: soda saline-alkali soil, soil desiccation cracking, salinity, crack length, prediction model

\section{Introduction}

Soil salinization is a typical kind of land degradation in arid and semiarid regions that can damage the soil structure and also dramatically affect the soil properties such as soil density, soil permeability, and soil strength, which can greatly reduce crop yield and seriously endanger

*e-mail: ren_jianhua@qq.com the ecological environment [1-2]. Currently, more than $7 \%$ of the earth's surface area has been salinized and the affected area still keeps increasing due to irrational human activities. Therefore, it is very important to identify the salt-affected areas and determine the soil salinity. In most instances, the conventional detections of soil salinity involve field sampling and laboratory analyzing [3-5], which often takes a long measurement cycle and a tedious testing process; electromagnetic induction sensor has also been extensively used to 
measure the salt content and distributions of saline soils through quickly obtaining soil electoral conductivity (EC) without contact [6-8], yet electromagnetic induction also has its defects due to its high instrument sensitivity and therefore is easily affected by soil properties and other external environments during the measurement process [9-10]. The remote-sensing method is also known as an effective approach for determining the spatial distributions of soil salinity, classifying the soil salinity levels due to the diagnostic spectral characteristics of different salt minerals [11-14]. However, it is often used only in a qualitative way because of the mixed pixel problems and the low spectral resolution of most remote-sensing data [15-17]. Therefore, it is urgent and important to develop a non-destructive and rapid method to measure the salt content based on the chemical and physical properties of the saline soils.

In nature, swelling soils commonly shrink and crack during water evaporation. Many researchers have focused on identifying and measuring characteristics of soil cracks, the influence factors, and the mechanism of desiccation cracking process of soils. For the characteristics of crack patterns of soil surface, early research mainly concentrated in the field of artificial measurement [18-19]; with the development of computer technology, more and more researchers have focused on the extractions of soil cracks using image processing technology since it is fast, accurate, and non-destructive. Tang et al. [20] carried out a laboratory-controlled experiment to study the effects of temperature, the evaporation rate, sample thickness, and soil type on the formation and development of soil desiccation cracks; DeCarlo et al. [21] studied the effect of sample box size on soil cracking by fractal theory and density correlation analysis, and the results showed that soil cracking duration and crack density decreased with the increasing size of the sample box, while the crack length and width presented a completely opposite trend. Zhang et al. [22] extracted several geometric characteristics of shrinkage crack network and quantitatively analyzed the effects of different moisture contents on the cracking process of clayey soils. Shit et al. [23] demonstrated an image processing technique for the automatic detection and analysis of surface soil cracks, and introduced the crack intensity factor as a descriptor of the extent of surficial cracking. After a series of laboratory tests, Yang et al. [24] showed that the fractal dimensions of surface crack patterns are well correlated with the surface crack ratio in a logarithmic equation, which can offer a new perspective on the quantitative understanding of cracking initiation and propagation in clayey soil under freeze-thaw cycles. Wang et al. [25] employed digital image processing and morphological algorithms to yield the geometric and fractal indexes (such as crack ratio, length, mean width, similarity degree, and box-counting fractal), and then used these indexes to analyze the dynamic cracking patterns subjected to wetting-drying cycles. Moreover, several researchers have tried to use new technology such as computed tomography (CT) for quantifying the cracks and analyzing the effect of soil cracking on soil structure and preferential flow [26-27].

Soda saline-alkali soil is a typical salinized soil, its soil texture is quite viscous, with a strong ability to shrink and crack - especially during water evaporation. However, unlike the traditional swelling soil, the moist soda saline-alkali soil contains the following four phases such as solid, liquid, gas, and salt minerals, which means salinity as the main chemical property can affect the cracking process to a large extent. Up to now, many researchers have studied the effects of salinity on the soil cracking process. After a series of studies about 32 kinds of saline-alkali soils, Smith et al. [28] confirmed that there are significant positive correlations between the linear expansion coefficient (COLE) and soil cation exchange capacity, with the correlation coefficient as high as 0.81; Zhang et al. [29] carried out a direct shear test using prepared soil samples with different contents of $\mathrm{NaHCO}_{3}$, and the results indicated that both cohesion and shear degree of the saline soils decreased with increasing salt content. Ren et al. [30-31] proposed the

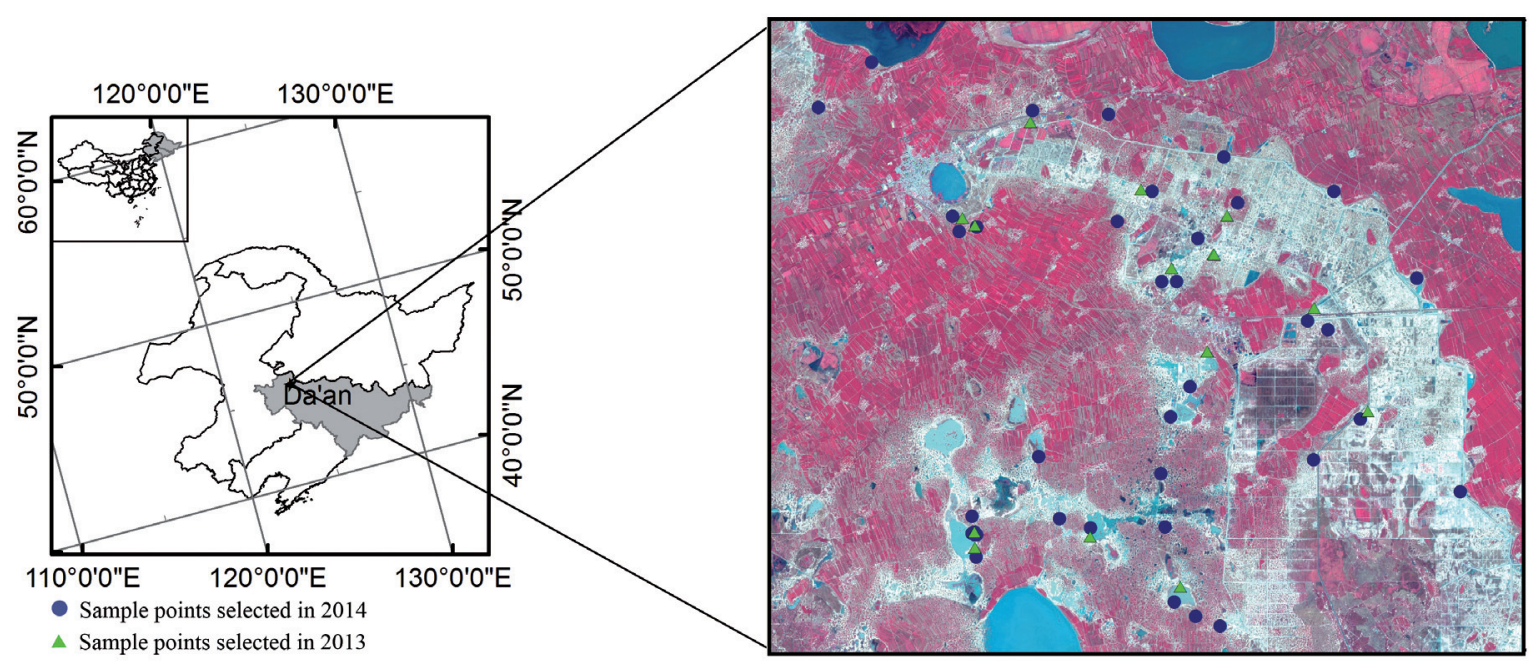

Fig. 1. Study area and sample points. 
texture feature of crack patterns as a new parameter to describe the crack conditions of soda-saline soils, and analyzed the quantitative relationship between the texture characteristics and soil parameters related to salinity. However, though the crack length is considered the most intuitive parameter to quantify soil cracking, the studies between crack length and soil salinity are still very rare. In this paper, we try to study the quantitative relationship between salinity and the crack length of soda saline-alkali soils in Songnen Plain by carrying out a laboratory-controlled experiment, and then establish the prediction model to explore the possibility of online prediction of the parameters related to soil salinity.

\section{Material and Methods}

\section{Study Area}

The Songnen Plain is located in Heilongjiang Province and Jilin Province of China, soil salinization is very serious and has caused a severely decline in soil fertility and affected the quality of farmland due to its inadequate drainage, high mineralization, and high groundwater level. The Songnen Plain is considered one of the three accumulation areas of soda saline-alkali soil in the world, but for the western region of Jilin Province the area of soda saline-alkali soil has already reached $170 \times 104 \mathrm{hm}^{2}$. In this paper, we chose a region in Da'an City of Jilin Province as the study area, which is located at $123^{\circ} 42^{\prime} 33^{\prime \prime} \mathrm{E} \sim 124^{\circ} 6^{\circ} 1^{\prime c} \mathrm{E}, 45^{\circ} 23^{\prime} 57^{\prime \prime} \mathrm{N} \sim 45^{\circ} 39^{\prime} 57^{\prime \prime} \mathrm{N}$ and has a representative type of heavy soda saline-alkali soil [32]. After considering the effects of heterogeneity and the environmental elements, we selected 57 sample points with different salinity levels in July 2013 and April 2014, with the distribution of sample points shown in Fig. 1. For each sample point we collected soil samples from the top $15 \mathrm{~cm}$ layer, the soil samples were air-dried, ground, and passed through a 2-mm sieve mesh, and then divided into two parts, and these two parts were used to determine physical and chemical properties and the following laboratory-controlled cracking experiment.

\section{Measurement of Soil Physical and Chemical Parameters}

In this study soil salinity was measured according to the experimental criteria proposed by Bao [33], including the $\mathrm{EC}$ value and $\mathrm{pH}$, and the contents of $\mathrm{Na}^{+}, \mathrm{K}^{+}, \mathrm{Ca}^{2+}, \mathrm{Mg}^{2+}, \mathrm{SO}_{4}^{2-}, \mathrm{HCO}_{3}^{-}, \mathrm{CO}_{3}^{2-}$, and $\mathrm{Cl}^{-}$of the soil sample solutions. In particular, the ion contents of soil samples were determined using soil extracts with a 1:5 water/soil mass ratio, where $\mathrm{K}^{+}$and $\mathrm{Na}^{+}$were determined using a flame photometer method; $\mathrm{Mg}^{2+}$ and $\mathrm{Ca}^{2+}$ were measured using EDTA complexometric titration; $\mathrm{Cl}^{-}$was extracted with $\mathrm{AgNO}_{3}$ solution titration; $\mathrm{HCO}_{3}{ }^{-}$and $\mathrm{CO}_{3}{ }^{2-}$ were measured based on a double indicator neutralization method; note that there is basically no $\mathrm{SO}_{4}^{2-}$ mineral in Songnen Plain, thus the content of $\mathrm{SO}_{4}^{2-}$ was neglected; moreover, the EC was measured by the conductometric method and $\mathrm{pH}$ was measured by the potentiometric method using soil suspension solutions with a 1:5 water/soil mass ratio. Besides, we also measured the particle size distributions of the experimental soil samples using a Malvern MS-200 laser particle size analyzer in this study [34].

\section{Cracking Experiment of Soil Samples}

In order to produce the crack images under controlled laboratory conditions, the soil samples were treated previously as saturated samples with the same initial

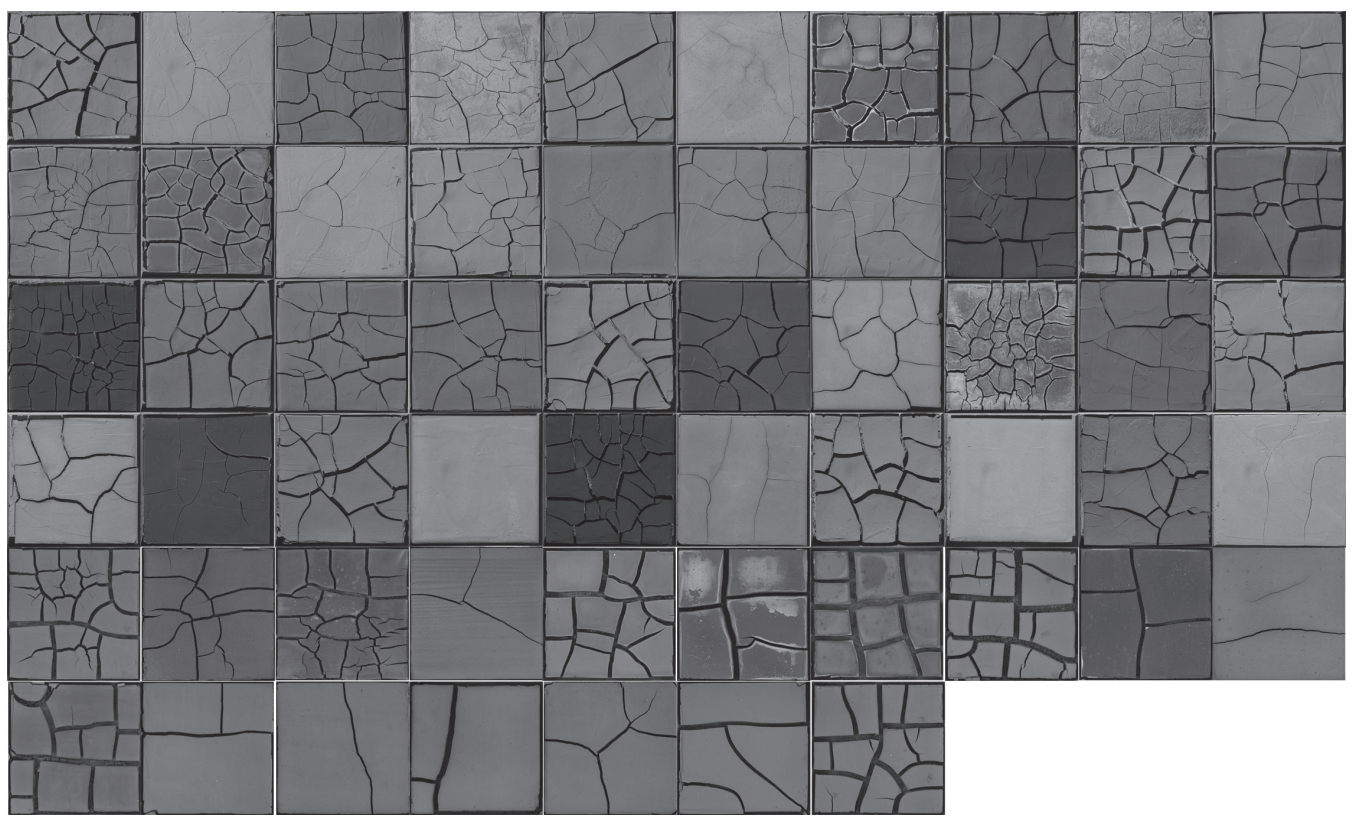

Fig. 2. Surface appearance of soil specimens after drying process. 
water mass content of $80 \%$. After that, the treated samples were mixed and put into a $50 \times 50 \times 3 \mathrm{~cm}$ wooden sample box and then the surfaces of the samples were flattened with a spatula as prepared specimens for the desiccation cracking test. Subsequently, the specimens were then put in laboratory conditions and air-dried until their masses no longer decreased, which indicated the drying process was completed (the dried specimens are shown in Fig. 2).

To obtain the crack patterns of all the dried soil specimens, a digital camera with fixed focus lens was installed on a metal experimental platform after the desiccation cracking process finished. For insurance of the same photo quality of the specimens, the lens of the camera must be faced vertically downward and kept $1 \mathrm{~m}$ above the floor. In order to ensure that the geometrical distortion was same for all the crack patterns of the specimens, a $50 \times 50 \mathrm{~cm}$ square area was determined according to the projection of the lens center on the ground. Noted that after considering the effects of the photographic environment, a standard colorimetric plate was used in this study to calibrate the white balance of the camera, a digital photometer was also used to measure the light sensitivity, and other camera parameters such as aperture size and shutter speed were also configured during the photographing process. Besides, a calibration plate with $50 \times 50 \mathrm{~cm}$ black and white mesh covered each specimen, a photo of which was taken for the following geometric distortion corrections.

\section{Digital Image Processing Method}

In order to extract the crack length of the dried specimens, a digital image processing method was used under the soft environment of MATLAB in this investigation (the whole extraction process is shown in Fig. 3). First, geometric distortion correction was performed on each crack pattern of soil specimen using the polynomial method and then cropped (Fig. 3a); secondly, the color pattern of each soil specimen was transformed into a grayscale one (Fig. 3b); thirdly, the grayscale image was treated into a binarizated image with a threshold (Fig. 3c) and then inversed (Fig. 3d), which indicated that black regions represented the aggregates and white regions represented the crack areas; fourthly, the small white noise was reduced over the aggregates based on the open operation with a threshold of 50 pixels (Fig. 3e); fifthly, a dilation operation was applied to the binary image with a given 20-pixel threshold to eliminate the narrow space with a distance smaller than 20 pixels between the cracks (Fig. 3f); after that, a skeletonization algorithm was then performed repeatedly by removing pixels from boundaries of the cracks until the cracks turned into one-pixel wide skeletons (Fig. 3g). Finally, another 30-pixel threshold was chosen to clip the extra spurs (considered as noises generated during skeletonization) with length smaller than the threshold (Fig. 3h). Following the processes above, crack length (CL) was then extracted based on the pixel number of binary crack skeleton of each crack pattern.

\section{Results and Discussion}

\section{Soil Properties}

Table 1 shows the statistical characteristics of the physical and chemical parameters of all soil specimens with salinity indicating the total ion content in the soil solution. It can be seen from the table that $\mathrm{pH}$ of the specimens range from 8.01 to 10.77 , and that $\mathrm{EC}$ is between $0.06 \mathrm{ds} / \mathrm{m}$ to $3.39 \mathrm{ds} / \mathrm{m}$, indicating that all soil samples show significant alkaline features [35]. Table 1 a)

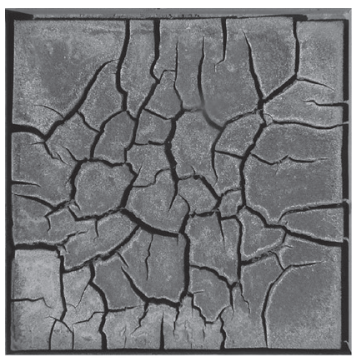

e)

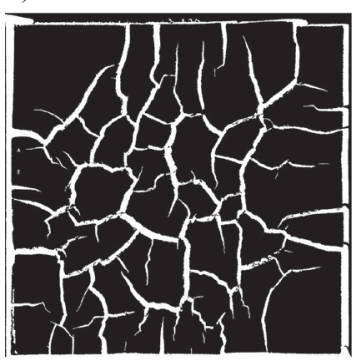

b)

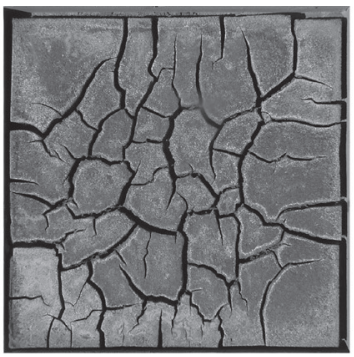

f)

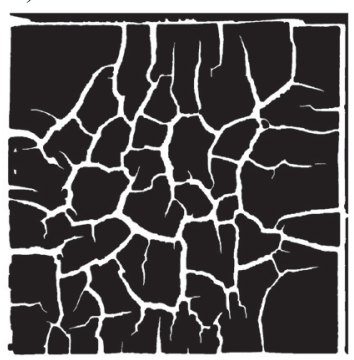

c)

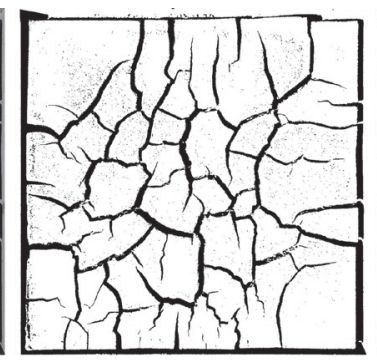

g)

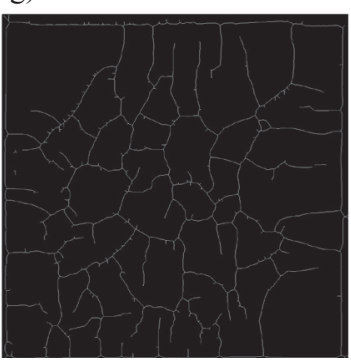

d)

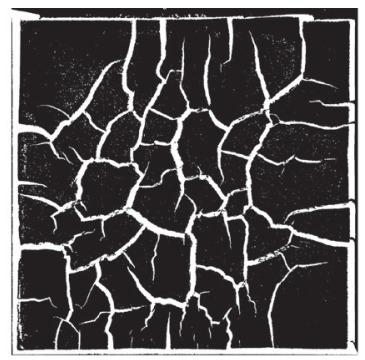

h)

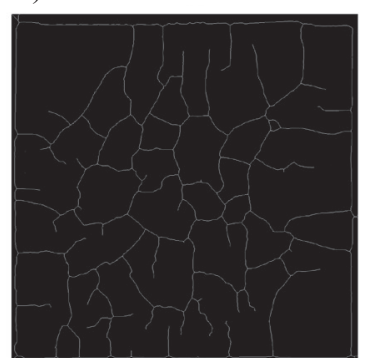

Fig. 3. Extraction process of crack length. 
Table 1. Statistical features of salt parameters.

\begin{tabular}{|c|c|c|c|c|c|c|c|}
\hline & Min & Max & Mean & Standard & CV(\%) & Skewness & Kurtosis \\
\hline $\mathrm{Na}^{+}\left(\mathrm{mg} \mathrm{g}^{-1}\right)$ & 0.12 & 14.12 & 3.367 & 3.288 & 97.64 & 1.49 & 2.08 \\
\hline $\mathrm{K}^{+}\left(\mathrm{mg} \mathrm{g}^{-1}\right)$ & 0.01 & 0.06 & 0.017 & 0.011 & 64.71 & 2.16 & 5.48 \\
\hline $\mathrm{Ca}^{2+} \& \mathrm{Mg}^{2+}\left(\mathrm{mg} \mathrm{g}^{-1}\right)$ & 0.01 & 1.6 & 0.539 & 0.318 & 59.01 & 1.18 & 1.66 \\
\hline $\mathrm{Cl}^{-}\left(\mathrm{mg} \mathrm{g}^{-1}\right)$ & 0.08 & 5.25 & 1.343 & 1.465 & 109.08 & 1.31 & 0.81 \\
\hline $\mathrm{CO}_{3}^{2-}\left(\mathrm{mg} \mathrm{g}^{-1}\right)$ & 0 & 5.51 & 1.776 & 1.562 & 87.95 & 1.01 & 0.11 \\
\hline $\mathrm{HCO}_{3}^{-}\left(\mathrm{mg} \mathrm{g}^{-1}\right)$ & 0.15 & 4.99 & 1.591 & 0.982 & 61.72 & 1.15 & 1.44 \\
\hline $\mathrm{EC}\left(\mathrm{ds} \mathrm{m}^{-1}\right)$ & 0.06 & 3.39 & 0.991 & 0.841 & 84.86 & 1.01 & 0.54 \\
\hline $\mathrm{pH}$ & 8.01 & 10.77 & 9.861 & 0.706 & 7.16 & -1.21 & 0.48 \\
\hline Salinity(mg g-1 $)$ & 1.06 & 29.73 & 8.631 & 6.441 & 74.63 & 1.22 & 1.43 \\
\hline Clay(\%) & 25.39 & 32.04 & 27.981 & 1.540 & 5.49 & 0.43 & -0.27 \\
\hline Silt(\%) & 28.72 & 40.41 & 35.191 & 3.181 & 9.03 & -0.12 & -0.82 \\
\hline Sand(\%) & 28.26 & 43.94 & 36.848 & 3.638 & 9.87 & -0.21 & -0.85 \\
\hline
\end{tabular}

$\mathrm{N}=57$

also shows that the total salt contents of the soil samples are very different, ranging from $1.06 \mathrm{mg} / \mathrm{g}$ to 29.73 , and the contents of the samples are also with a large range among different ions: $\mathrm{Na}^{+}$is the dominent soil cation with content much higher than those of $\mathrm{K}^{+}, \mathrm{Ca}^{2+}$, and $\mathrm{Mg}^{2+}$ in the samples; the soil anions are mainly $\mathrm{Cl}^{-}, \mathrm{HCO}_{3}^{-}$, and $\mathrm{CO}_{3}^{2-}$, with their contents closely related to the ECs and total salt content, thus it can be ensured that the salt

Table 2. Crack lengths of soil specimens.

\begin{tabular}{|c|c|c|c|c|c|}
\hline Number & Crack length $(\mathrm{cm})$ & Number & Crack length $(\mathrm{cm})$ & Number & Crack length $(\mathrm{cm})$ \\
\hline 1 & 480.31 & 20 & 441.03 & 39 & 425.55 \\
\hline 2 & 354.08 & 21 & 797.18 & 40 & 350.42 \\
\hline 3 & 516.78 & 22 & 546.45 & 41 & 582.15 \\
\hline 4 & 525.84 & 23 & 502.14 & 42 & 495.96 \\
\hline 5 & 411.45 & 24 & 432.88 & 43 & 685.42 \\
\hline 6 & 299.58 & 25 & 488.03 & 44 & 315.15 \\
\hline 7 & 517.16 & 26 & 457.26 & 45 & 444.19 \\
\hline 8 & 437.03 & 27 & 385.60 & 46 & 391.42 \\
\hline 9 & 674.54 & 28 & 701.83 & 47 & 523.96 \\
\hline 10 & 389.52 & 29 & 411.52 & 48 & 461.65 \\
\hline 11 & 609.56 & 30 & 409.88 & 49 & 418.46 \\
\hline 12 & 625.22 & 31 & 407.00 & 50 & 321.81 \\
\hline 13 & 333.13 & 32 & 411.21 & 51 & 429.88 \\
\hline 14 & 491.47 & 33 & 468.92 & 52 & 318.42 \\
\hline 15 & 335.66 & 34 & 200.00 & 53 & 295.69 \\
\hline 16 & 378.67 & 35 & 593.77 & 54 & 284.88 \\
\hline 17 & 390.44 & 36 & 321.86 & 55 & 306.15 \\
\hline 18 & 479.76 & 37 & 479.82 & 56 & 322.12 \\
\hline 19 & 550.60 & 38 & 200.00 & 57 & 492.38 \\
\hline
\end{tabular}


mineralization of soda saline-alkali soil in Songnen Plain is mainly composed of $\mathrm{NaCl}, \mathrm{NaHCO}_{3}$, and $\mathrm{Na}_{2} \mathrm{CO}_{3}$. In addition, Table 1 also shows that particle size distribution of the samples is nearly the same, especially for the clay particles with size below $0.005 \mathrm{~mm}$, there were no significant differences observed for the soil samples with the standard deviation and coefficient of variation only 1.54 and $5.49 \%$, respectively.

\section{Crack Lengths}

Table 2 shows the crack length extraction results of all the specimens after their desiccation cracking process finished completely. It can be seen that the crack lengths of all dried specimens are significantly different from each other with a range from $200 \mathrm{~cm}$ to $797 \mathrm{~cm}$, indicating that the crack length is very sensitive to the response of the salinity levels. Moreover, Table 3 gives the results of correlation analysis between crack length and the parameters related to salt content, showing that the crack length is highly related to the contents of salt parameters, especially for $\mathrm{EC}$, salinity, and $\mathrm{Na}^{+}$with correlation coefficient above 0.9 ; however, there are weak relationships between crack length and the contents of $\mathrm{K}^{+}, \mathrm{Ca}^{2+}$ and $\mathrm{Mg}^{2+}$ because of their low content and relatively high errors during measurement.

\section{Effect of Salinity on Soil Cracking Process}

Many researchers have shown that the desiccation cracking process of clayey soil is mainly affected by the mechanical properties of soil matrix, such as tensile strength, surface energy, and substrate suction [3637], which are determined by the soil mineral type and the clay content to a large extent [38]. Moreover, the mechanical properties mentioned above are also affected by environmental conditions such as initial water content, humidity, temperature, and other experimental conditions as well as the thickness, material, size, and shape of the sample box. In this study, the distribution of soil samples was within a small range, which therefore ensured that the clay content and the mineral compositions were kept nearly the same; since the ecological environment, the geographical environment, the hydrologic process, and the climate are all stable with very small variations during the soil-forming process of soda saline-alkali soils in Songnen Plain, the clay contents of the soil samples in the present study are from $25.39 \%$ to $32.04 \%$, which is quite in correspondence with the clay content range from $24.13 \%$ to $35.9 \%$ as measured by Wang et al. [39], and that from $20 \%$ to $29 \%$ measured by Zhang et al. [40]. Zhang also studied the effects of clay content and clay
Table 4. Linear equations between salt parameters and crack length of soil specimens.

\begin{tabular}{|c|c|c|}
\hline Salt parameters & Linear models & $\mathrm{R}^{2}$ \\
\hline $\mathrm{pH}$ & $\mathrm{y}=0.0039 \mathrm{x}+8.0991$ & 0.4405 \\
\hline $\mathrm{EC}$ & $\mathrm{y}=0.0064 \mathrm{x}-1.8775$ & 0.8395 \\
\hline $\mathrm{Na}^{+}$ & $\mathrm{y}=0.0257 \mathrm{x}-8.0069$ & 0.8515 \\
\hline $\mathrm{Cl}^{-}$ & $\mathrm{y}=0.0101 \mathrm{x}-3.1746$ & 0.6602 \\
\hline $\mathrm{CO}_{3}^{2-}$ & $\mathrm{y}=0.0093 \mathrm{x}-2.5823$ & 0.5985 \\
\hline Salinity & $\mathrm{y}=0.0511 \mathrm{x}-14.2113$ & 0.8961 \\
\hline
\end{tabular}

$\mathrm{N}=38$

mineral type on the shrinkage of soda soils in Songnen Plain, and the measured results showed that due to the original minerals of soda saline-alkali soils in Songnen Plain composed by quartz and feldspar with content from $87.6 \%$ to $91.6 \%$ and the second mineral composed by iillite/smectite formation with interlaying ratio above 0.5 , the activity index is only between 0.33 and 0.48 , which means that both the clay mineral and clay content can hardly affect the desiccation cracking process of soda saline-alkali soils in Songnen Plain. In this study, the experiment was carried out under the same controlled test conditions with the sample presentation process being absolutely identical, indicating that the salt content of the soil was the determinant of the soil desiccation cracking process.

The measured salt parameters and the obtained crack lengths indicated that the increasing salt content would result in larger crack length at the surface of soil specimens, shown in Table 4. One possible explanation for such an outcome could be related to the effect of chemical ions on the soil particles. This is due to when the saline soil slurries evaporated, soil particles interacted, and exchanged cations between soil particles especially for $\mathrm{Na}^{+}$, which is the main component of soda salinized soil solution with large hydrolysis radius, in particular, a relatively thick-bonded water film could form between soil particles (the higher salt contents were within soil solution, the thicker film generated between soil particles), and it increased the distance between soil particles and meanwhile decreased the cementation, which made both soil cohesion and tensile strength decrease rapidly. In addition, the bonded water film also decreased the internal friction angle between soil particles, resulting in a significant cracking process of soil specimens [41-42]. In addition, the trend between salinity and crack length can also be described by considering a phenomenon

Table 3. Results of correlation analysis between salt parameters.

\begin{tabular}{|c|c|c|c|c|c|c|c|c|c|}
\hline & $\mathrm{pH}$ & $\mathrm{EC}$ & $\mathrm{Na}^{+}$ & $\mathrm{K}^{+}$ & $\mathrm{Ca}^{2+} \& \mathrm{Mg}^{2+}$ & $\mathrm{HCO}_{3}^{-}$ & $\mathrm{CO}_{3}^{2-}$ & $\mathrm{Cl}^{-}$ & Salinity \\
\hline Crack length & 0.66 & 0.92 & 0.91 & 0.25 & 0.24 & 0.62 & 0.76 & 0.83 & 0.94 \\
\hline
\end{tabular}

$\mathrm{N}=57$ 
Table 5. Evaluation formulas for predictive precision models.

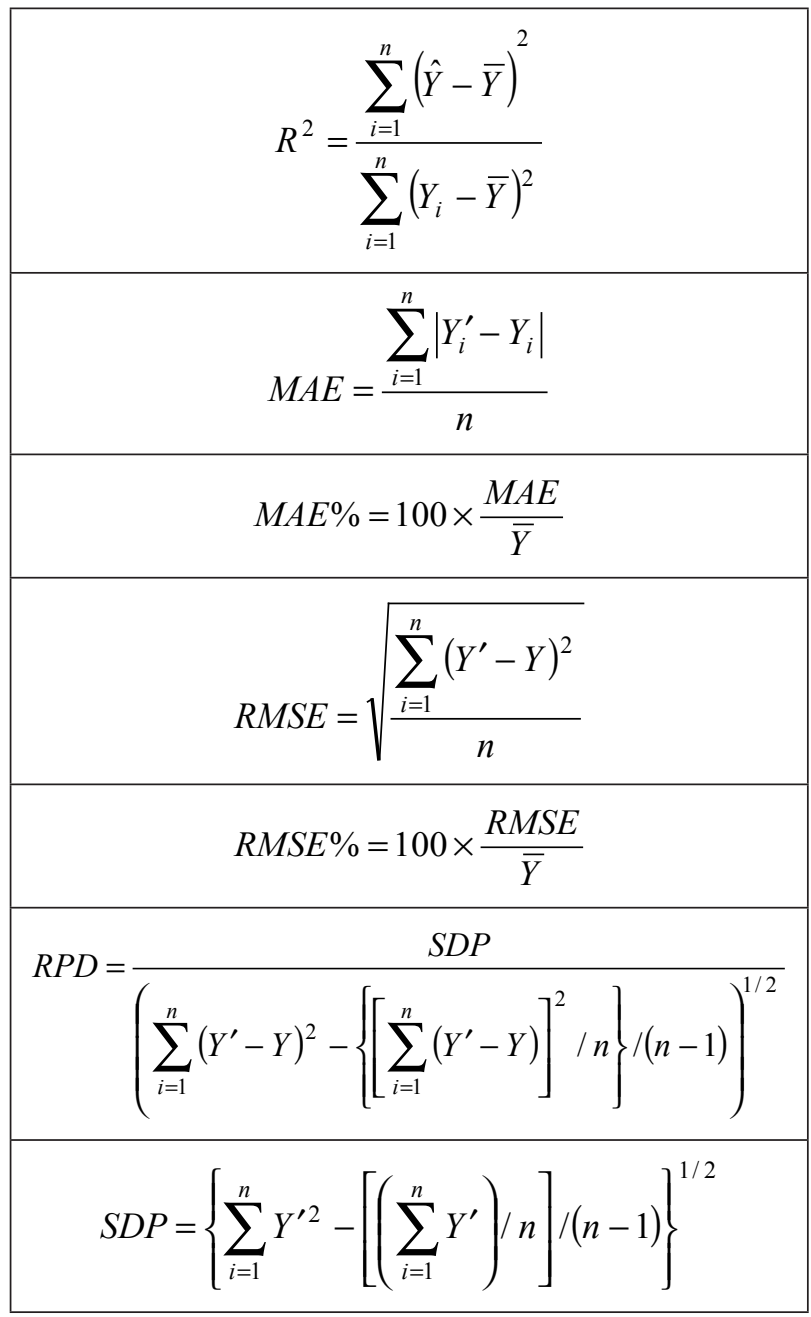

referred to as the "diffuse double layer" (DDL), which has a significant effect on soil and is affected by soil salinity - especially ion content. When the salinity levels of soil specimens increase, the DDL thickness becomes thinner, which plays an important role in soil properties and directly controls the shrinkage and development of surface cracking during water evaporation [43-45].

\section{Verification Experiment}

In order to verify the reliability of the relationship between the crack lengths and the parameters related to salt content of all the specimens proposed in this study, 57 soil samples were divided into 19 groups according to total salt content. After that, 2 random samples were chosen from each group as modeling samples, and the remaining 19 samples were selected as validation samples. The 38 samples for modeling were used to establish the linear model of soil parameters related to salt content such as $\mathrm{pH}, \mathrm{EC}, \mathrm{Na}^{+}, \mathrm{CO}_{3}{ }^{2-}, \mathrm{Cl}^{-}$, and salinity, and the linear models are shown in Table 4.

Afterward, the crack lengths of all the verification samples were put into the linear models of soil parameters established above, and then predicted the salt parameters of $\mathrm{pH}, \mathrm{EC}, \mathrm{Na}^{+}, \mathrm{CO}_{3}{ }^{2-}, \mathrm{Cl}^{-}$, and salinity based on the linear models. In order to evaluate the stability and reliability of each linear prediction model, evaluation indexes of the fitting results were calculated between the measured values and the prediction values of the salt parameters. We especially calculated the coefficient of determination $\left(\mathrm{R}^{2}\right)$, the mean absolute error (MAE), the relative mean absolute error (MAE\%), the root-mean-square error (RMSE), the relative root-mean-square error (RMSE\%)
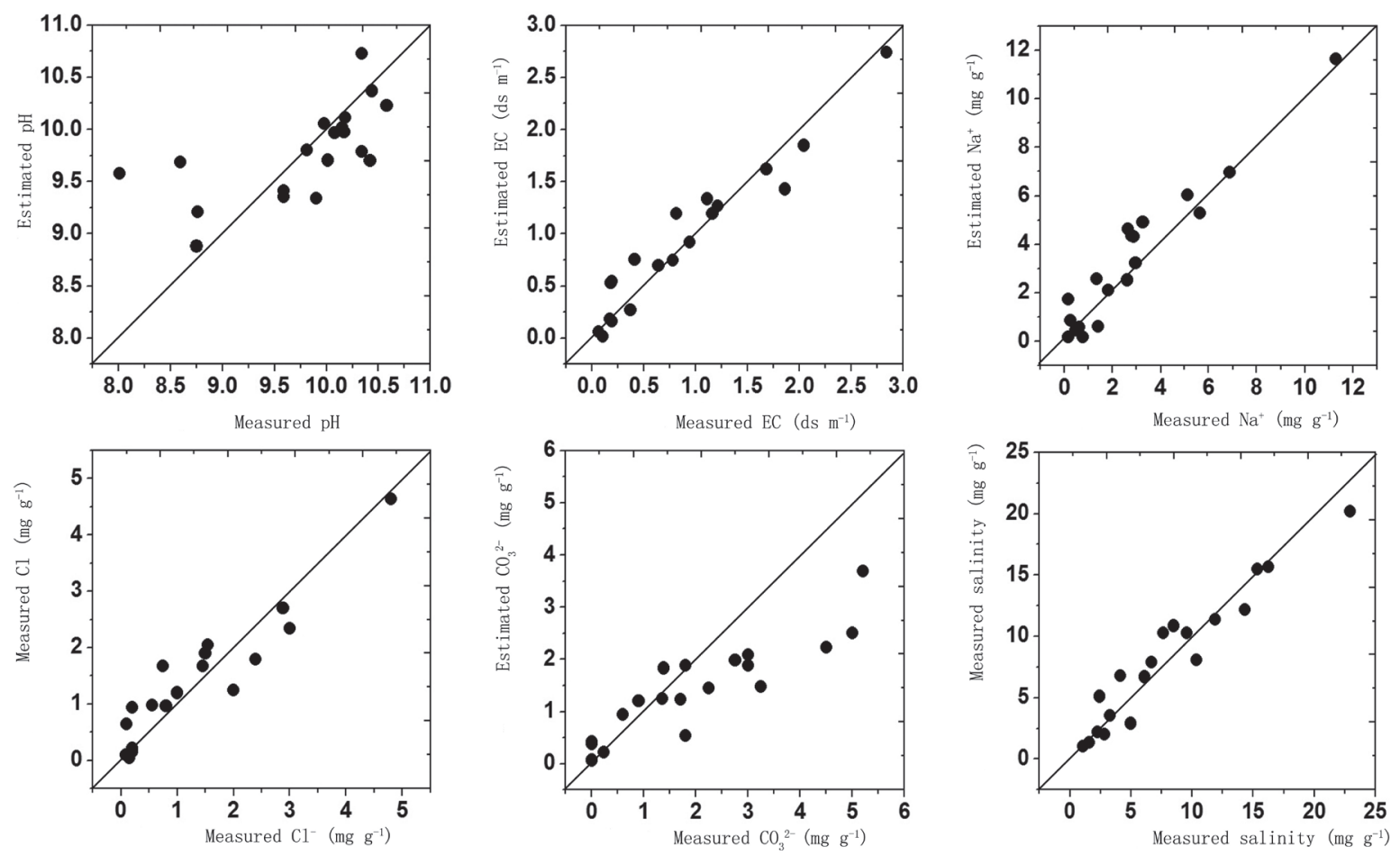

Fig. 4. Linear regression between measured data and estimated data. 
Table 6. Evaluation indexes of linear models for different salt parameters.

\begin{tabular}{|c|c|c|c|c|c|c|c|}
\hline & $\mathrm{R}^{2}$ & $\mathrm{ME}$ & $\mathrm{RMSE}$ & $\mathrm{RMSE} \%$ & MAE & MAE\% & RPD \\
\hline $\mathrm{pH}$ & 0.42 & 0.41 & 1.54 & 65.53 & 0.38 & 53.88 & 1.06 \\
\hline $\mathrm{EC}$ & 0.93 & 0.96 & 0.21 & 23.69 & 0.15 & 17.12 & 5.40 \\
\hline $\mathrm{Na}^{+}$ & 0.92 & 0.88 & 0.96 & 34.56 & 0.73 & 26.01 & 4.50 \\
\hline $\mathrm{Cl}^{-}$ & 0.88 & 0.87 & 0.45 & 36.08 & 0.35 & 28.27 & 3.79 \\
\hline $\mathrm{CO}_{3}^{2-}$ & 0.78 & 0.54 & 1.09 & 53.66 & 0.82 & 40.14 & 1.82 \\
\hline Salinity & 0.92 & 0.92 & 1.66 & 20.69 & 1.29 & 16.22 & 5.72 \\
\hline
\end{tabular}

$\mathrm{N}=19$

and the predicted ratio of deviation (PRD). The formulas for evaluation indexes are shown in Table 5, where $Y$ and $Y^{\prime}$ are the measured values and estimated values by models, $\bar{Y}$ and $\bar{Y}^{\prime}$ are the mean values of $Y$ and $Y^{\prime}$, and $\mathrm{n}$ stands for the sample number. In the above evaluation index parameters, MAE and RMSE are to determine the absolute estimation error between the predicted values and the measured values; the relative indexes (MAE\% and $\mathrm{RMSE} \%$ ) are for further comparing the evaluation ability among different salt parameters; the RPD is used as the indicator to analyze the matching degree between predicted and measured values. According to the criteria given by Farifteh et al. [46], the linear model can be considered as accurate when $\mathrm{R}^{2}>0.91$ and RPD $>2.5$; the model has relative high predictability when $0.82<\mathrm{R}^{2}<0.9$ and $2<\mathrm{RPD}<2.5$; when $\mathrm{R}^{2}$ is between 0.66 and 0.81 and $R P D>1.5$, the prediction values only have a certain estimation accuracy; however, when $\mathrm{R}^{2}<0.65$ and $\mathrm{RPD}<1.5$, the linear model shows very poor prediction ability in practical applications.

Table 6 gives the results of the evaluation indexes between the measured values and the predictive values of the samples for verification, it can be seen that the linearity between crack length and the salt parameters such as $\mathrm{Na}^{+}, \mathrm{Cl}-$, EC, and salinity is very good, with $\mathrm{R}^{2}>0.91$ and $\mathrm{RPD}>2.5$; that the linearity of crack length and $\mathrm{CO}_{3}{ }^{2-}$ also has certain prediction accuracy, but the $\mathrm{RMSE} \%$ of $56.67 \%$ and MAE\% of $40.14 \%$ indicates the prediction models are of poor stability and reliability; that for $\mathrm{pH}$, the $\mathrm{R}^{2}$ is only 0.42 and RPD is only 1.06 , indicating that the $\mathrm{pH}$ prediction model is not reliable with very poor accuracy.

Fig. 4 shows the fitting results between prediction values of $\mathrm{pH}, \mathrm{EC}, \mathrm{Na}^{+}, \mathrm{CO}_{3}^{2-}, \mathrm{Cl}^{-}$, salinity, and the measured values of them, respectively. From Fig. 4 it can be seen that there was a significant underestimation phenomenon of $\mathrm{pH}$ and $\mathrm{CO}_{3}{ }^{2-}$, which may be because the hydrolysis process of $\mathrm{CO}_{3}{ }^{2-}$ made its content turning instable in soil samples. In addition, Fig. 4 and Table 6 also show high prediction ability for $\mathrm{Na}^{+}, \mathrm{Cl}^{-}, \mathrm{EC}$, and salinity, which also indicates that the crack length in the scale of $50 \times 50 \mathrm{~cm}$ can well represent the cracking extent of soda saline-alkali soils under natural conditions.

\section{Conclusions}

In this study, 57 samples of soda saline-alkali soil with different salinity levels were selected form Da'an City, Jilin Province in July 2013 and April 2014, and a laboratory controlled experiment was then carried out simulating the shrinkage cracking process of these soil samples. After that, the crack lengths of all these specimens were extracted using image processing technique and then the crack lengths were analyzed with EC, $\mathrm{pH}$, and contents of different ions. The results showed that the crack length of soda saline-alkali soil was linearly related to the content of $\mathrm{Na}^{+}, \mathrm{EC}, \mathrm{Cl}^{-}$, and salt content, while $\mathrm{pH}, \mathrm{CO}_{3}^{2-}$, and $\mathrm{HCO}_{3}^{-}$showed a relatively poor relationship. In this paper, we also analyzed the effects of soil salinity on the process of water evaporation and the shrinkage cracking process of soda-type salinized soil with certain clay type in Songnen Plain based on the correlation analysis of crack length and salt parameters considering the type and content of the clay minerals. Finally, we used the soil samples to establish regression models for predicting the salt parameters and verifying the predictive ability of these models, the fitting results showed that the crack length is of high predictive accuracy for $\mathrm{Na}^{+}, \mathrm{Cl}^{-}, \mathrm{EC}$, and salinity, but with poor predictive accuracy for $\mathrm{pH}, \mathrm{HCO}_{3}^{-}$, and $\mathrm{CO}_{3}^{2-}$, the results also indicates that the specimen size of $50 \times 50 \mathrm{~cm}$ can well characterize the cracking extent of the soil surface in Songnen Plain.

\section{Acknowledgements}

This work was supported by the National Natural Science Foundation of China (Nos. 41601382 and 41671350) and the Basic Research Foundation of Universities in Heilongjiang Province of China (No. 2017-KYYWF-0145). We are very grateful for the assistance provided by Professor Zhichun Wang from the Da'an Alkaline Ecological Experimental Station, Chinese Academy of Science.. 


\section{Conflict of Interest}

The authors declare no conflict of interest.

\section{References}

1. LI J., PU L., HAN M., ZHU M., ZHANG R., XIANG Y. Soil salinization research in China: advances and prospects. Journal of Geographical Sciences. 24 (5), 943, 2014.

2. RUKHOVICH D.I., SIMAKOVA M.S., KULYANITSA A.L., BRYZZHEV A.V., KOROLEVA P.V., KALININA N.V., CHERNOUSENK G.I., VIL'CHEVSKAYA E.V., DOLININA E.A., RUKHOVICH S.V. The influence of soil salinization on land use changes in azov district of Rostov oblast. Eurasian Soil Science. 50 (3), 276, 2017.

3. SHE D., GAO X., WANG P., XU W., LIU Y., LIU Y. Comparison of soil hydraulic properties with different levels of soil salinity and sodicity. Arabian Journal of Geosciences. 8 (8), 5351, 2015.

4. MESSAD A., MOUSSAI B. Effect of water salinity on Atterberg limits of El-Hodna sabkha soil. Bulletin of Engineering Geology and the Environment. 75 (1), 301, 2016.

5. HASBULLAH H., MARSCHNER P. Residue properties influence the impact of salinity on soil respiration. Biology and Fertility of Soils. 51 (1), 99, 2015.

6. ROUT S., RAVI P.M., KUMAR A., TRIPATHI R.M. Study on speciation and salinity-induced mobility of uranium from soil. Environmental Earth Sciences. 74 (3), 2273, 2015.

7. COPPOLA A., SMETTERM K., AJEEL A., SAEED A., DRAGONETTI G., COMEGNA A., LAMADDALENA N., VACCA A. Calibration of an electromagnetic induction sensor with time-domain reflectometry data to monitor rootzone electrical conductivity under saline water irrigation. European Journal of Soil Science. 67 (6), 737, 2016.

8. GANJEGUNTE G.K., SHENG Z., CLARK J.A. Soil salinity and sodicity appraisal by electromagnetic induction in soils irrigated to grow cotton. 25 (3), 228, 2014.

9. JADOON K.Z., MOGHADAS D., JODOON A., MISSIMER T.M., AL-MASHHARAWI S.K., MCCABE M.F. Estimation of soil salinity in a drip irrigation system by using joint inversion of multicoil electromagnetic induction measurements. Water Resources Research. 51 (5), 3490, 2015.

10. HERRERO J., HUDNALL W.H. Measurement of soil salinity using electromagnetic induction in a paddy with a densic pan and shallow water table. Paddy and Water Environment. 12 (1), 263, 2014.

11. LI J., PU L., HAN M., ZHU M., ZHANG R., XIANG Y. Soil salinization research in China: advances and prospects. Journal of Geographical Sciences. 24 (5), 943, 2014.

12. SIDIKE A., ZHAO S., WEN Y. Estimating soil salinity in Pingluo County of China using Quickbird data and soil reflectance spectra. Geoinformation. 26 (2), 156, 2014.

13. TRIBI F.H., BOUAZIZ M., BENZINA M., BOUAZIZ S. Detection of terrain indices to soil salinity and mapping salt-affected soils using remote sensing and geostatistical techniques. Environmental Monitoring and Assessment. 189 (4), 177, 2017.
14. MENG L., ZHOU S., ZHANG H., BI X. Estimating soil salinity in different landscapes of the Yellow River Delta through Landsat OLI/TIRS and ETM+ data. Journal of Coastal Conservation. 20 (4), 271, 2016.

15. EL-BATTAY A., BANNARI A., HAMEID N.A., ABAHUSSAIN A.A. Comparative study among different semi-empirical models for soil salinity prediction in an arid environment using OLI Landsat-8 data. Advances in Remote Sensing. 1, 23, 2017.

16. METTERNICHT G.I., ZINCK J.A. Remote sensing of soil salinity: potentials and constraints. Remote Sensing of Environment. 85 (1), 1, 2003.

17. LI H., WEBSTER R., SHI Z. Mapping soil salinity in the Yangtze delta: REML and universal kriging (E-BLUP) revisited. Geoderma. 237-238, 71, 2015.

18. RINGROSE-VOASE A.J., SANIDAD W.B. A method for measuring the development of surface cracks in soilsapplication to crack development after lowland rice. Geoderma. 71 (3-4), 245, 1996.

19. NOVAK V. Soil-crack characteristics-estimation methods applied to heavy soil in the NOPEX area. Agricultural and Forest Meteorology. 98 (1), 501, 1999.

20. TANG C., SHI B., LIU C., SUO W., Gao L. Experimental characterization of shrinkage and desiccation cracking in thin clay layer. Applied Clay Science. 52 (1), 69, 2011.

21. DECARLO K.F., SHOKRI N. Effects of substrate on cracking patterns and dynamics in desiccating clay layers. Water Resources Research. 50 (4), 3039, 2014.

22. ZHANG Z., WANG C., ZHU C., ZHU W., WU C. Geometric characteristics of shrinkage crack network in soil. Journal of China University of Geosciences. 39 (10), 1565, 2014. (in Chinese with English abstract)

23. SHIT P.K., BHUNIA G.S., MAITI R. Soil crack morphology analysis using image processing techniques. Modeling Earth Systems \& Environment. 1 (4), 1, 2015.

24. YANG L., LIU S., WENG L., WANG L., LI Z., XU L. Fractal analysis of cracking in a clayey soil under freezethaw cycles. Engineering Geology. 208 (24), 93, 2016.

25. WANG C., ZHANG Z., LIU Y., FAN S. Geometric and fractal analysis of dynamic cracking patterns subjected to wetting-drying cycles. Soil and Tillage Research. 170, 1, 2017.

26. ZHANG Z.B., PENG X., ZHOU H., LIN H., SUN H. Characterizing preferential flow in cracked paddy soils using computed tomography and breakthrough curve. Soil and Tillage Research. 146, 53, 2015.

27. WANG Y., Li X., ZHANG B., WU Y. Meso-damage cracking characteristics analysis for rock and soil aggregate with CT test. Science China (Technological Sciences). 57 (7), 1361, 2014.

28. SMITH C.W., HADAS A., DANA J., KOYUMDJISKYA $\mathrm{H}$. Shinkage and atterberg limits in relation to other properties of principal soil tupes in Isreal. Geoderma. 35 (1), 47, 1985.

29. ZHANG G., YU Q., WEI G., CHEN B., TANG L., HU C., LI J., CHEN H. Basic property of Songnen Plain salinealkali soil. Hydrogeology \& Engineering Geology. 2, 37, 2007. (Chinese with English abstract)

30. REN J., LI X., ZHAO K. Quantitative analysis of relationships between crack characteristics and properties of soda-saline soils in Songnen Plain, China. Chinese Geographical Science. 25 (5), 591, 2015.

31. REN J., LI X., ZHAO K., FU B., JIANG T. Study of an online measurement method for the salt parameters of sodasaline soils based on the textures of cracks. Geoderma. 263, 60, 2016. 
32. YANG F., AN F., YANG H., WANG Z. Characteristics of leaf photosynthesis in Leymus chinensis grown in sodic soil area of the Songnen Plain, at different groundwater depths. Acta Ecologica Sinica. 36 (6), 1591, 2016. (Chinese with English abstract)

33. BAO S. Agricultural chemistry analysis of soils. Beijing: Chinese Agriculture Press. 152, 2000.

34. PENG H., HORTON R., LEI T., DAI Z., WANG X. A modified method for estimating fine and coarse fractal dimensions of soil particle size distributions based on laser diffraction analysis. Journal of Soils and Sediments. 15 (4), 937, 2015.

35. CHHABRA R. Classification of salt-affected soils. Arid Land Research and Management. 19 (1), 61, 2005.

36. GUI Y.L., HU W., ZHAO Z.Y., ZHU X. Numerical modeling of a field soil desiccation test using a cohesive fracture model with Voronoi tessellations. Acta Geotechnica. 12, 1, 2017.

37. MARRA T., SUIJS J. Crack patterns in clayey soils: Experiments and modeling. International Journal for Numerical and Analytical Methods in Geomechanics. 36 (11), 1410, 2012.

38. BOVIN P., GARNIER P., TESSIER D. Relationship between clay content, clay type and shrinkage properties of soil samples. Soil Science Society of America Journal. 68 (4), 1145, 2004.

39. WANG W., WANG Q., ZHANG J., CHEN H. An Experiment Study of the Fundamental Property of the Carbonate-saline Soil in West of Jilin Province. Journal of Beijing University of Technology. 37 (2), 217, 2011. (Chinese with English abstract)

40. ZHANG G., LI J., YU Q., ZHANG B., YANG R., Chen $H$. Influence of salt content on shearing strength of the carbonate saline soil in Songnen Plain. The Chinese Journal of Geological Hazard and Control. 19 (1), 128, 2008. (Chinese with English abstract)

41. AKSENOV V.I., KAL'BERGENOV R.G., LEONOV A.R. Strength characteristics of frozen saline soils. Soil Mechanics and Foundation Engineering. 40 (2), 55, 2003.

42. JEONG S., LOCAT J., LEROUEIL S. The effects of salinity and shear history on the rheological characteristics of illite-rich and Na-montmorillonite-rich clays. Clays and Clay Minerals. 60 (2), 108, 2012.

43. DECARLO K.F., SHOKRI N. Salinity effects on cracking morphology and dynamics in 3-D desiccating clays. Water Resources Research. 50 (4), 3052, 2014.

44. SHOKRI N., ZHOU P., KESHMIRI A. Patterns of desiccation cracks in saline bentonite layers. Transport in Porous Media. 110 (2), 333, 2015.

45. ZHANG X., CHEN Y., YE W., CUI Y., DENG Y., CHEN B. Effect of salt concentration on desiccation cracking behaviour of GMZ bentonite. Environmental Earth Sciences. 76 (15), 531, 2017.

46. FARIFTEH J., VAN DER MEER F., ATZBERGER C., CARRANZA E.J.M. Quantitative analysis of saltaffected soil reflectance spectra: A comparison of two adaptive methods (PLSR and ANN). Remote Sensing of Environment. 110 (1), 59, 2007. 